\title{
Inverse Electron-Demand Diels-Alder Methylcellulose Hydrogels Enable the Co-Delivery of Chondroitinase ABC and Neural Progenitor Cells
}

Vianney Delplace, ${ }^{\mathrm{a}, *}$ Andrew J. Pickering, ${ }^{\mathrm{a}, *}$ Marian H. Hettiaratchi, ${ }^{\mathrm{a}}$ Spencer Zhao, ${ }^{a}$ Tove Kivijärvi, ${ }^{\text {a,b }}$ Molly S. Shoichet ${ }^{a, c}$

*These two authors contributed equally

aDepartment of Chemical Engineering \& Applied Chemistry, University of Toronto, 200 College Street, Toronto, ON M5S 3E5, Canada

${ }^{b}$ Department of Fibre and Polymer Technology, KTH Royal Institute of Technology, SE-100 44, Stockholm, Sweden

'Institute of Biomaterials and Biomedical Engineering, University of Toronto, 164 College St., Toronto, ON M5S 3G9, Canada 


\section{Supplemental Figures}

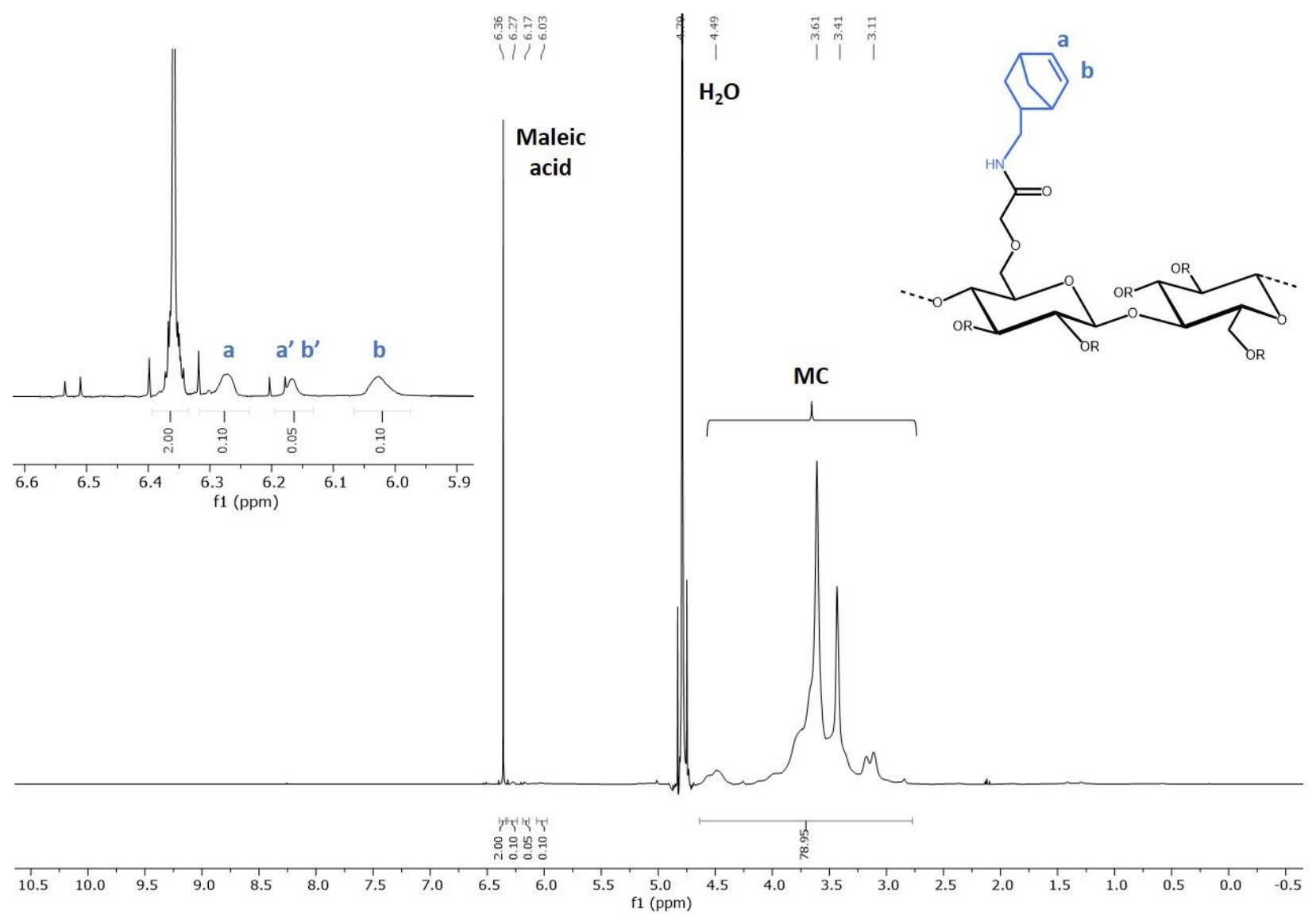

Figure S1. ${ }^{1} \mathrm{H}$ NMR spectrum of MC-Norbornene using maleic acid as an internal standard $\left(\mathrm{D}_{2} \mathrm{O}, 500 \mathrm{MHz}\right)$, showing a norbornene substitution of $82 \pm 27 \mu \mathrm{mol} / \mathrm{g}$. The amount of immobilized norbornene was also determined indirectly by first reacting $\mathrm{MC}$ norbornene with tetrazine-PEG-biotin and then quantifying biotin. The norbornene substitution was of $80 \mu \mathrm{mol}$ Norb/g of MC-Norb, confirming the NMR results. 
A

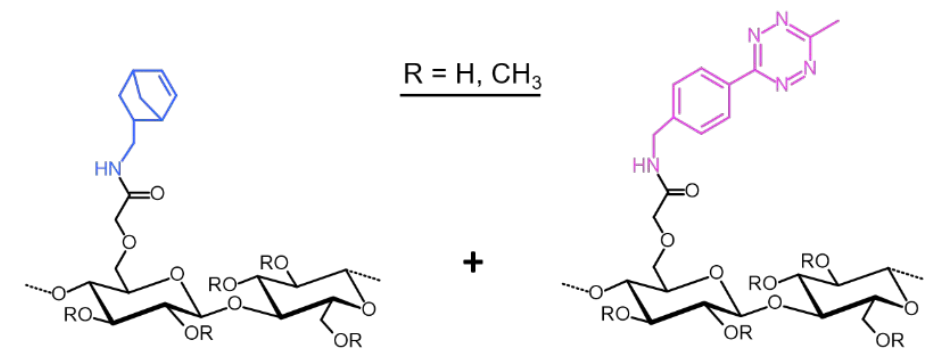

MC-Norbornene
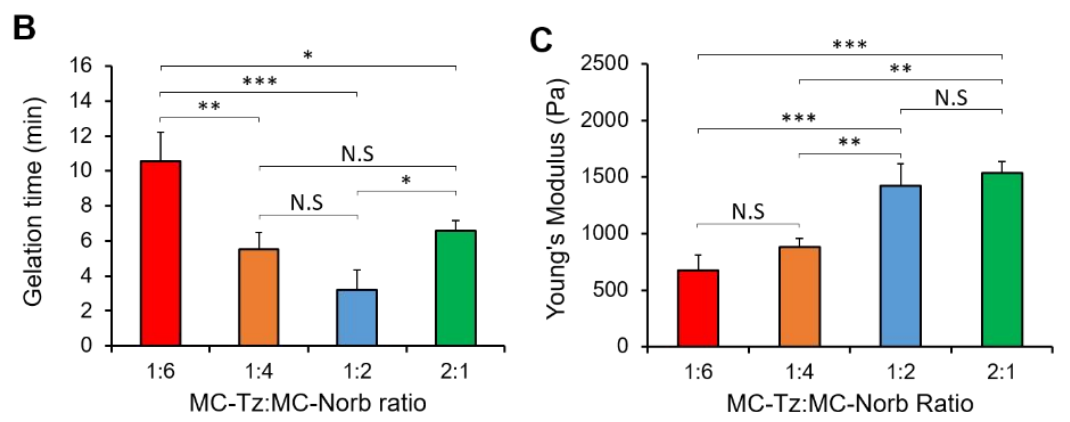
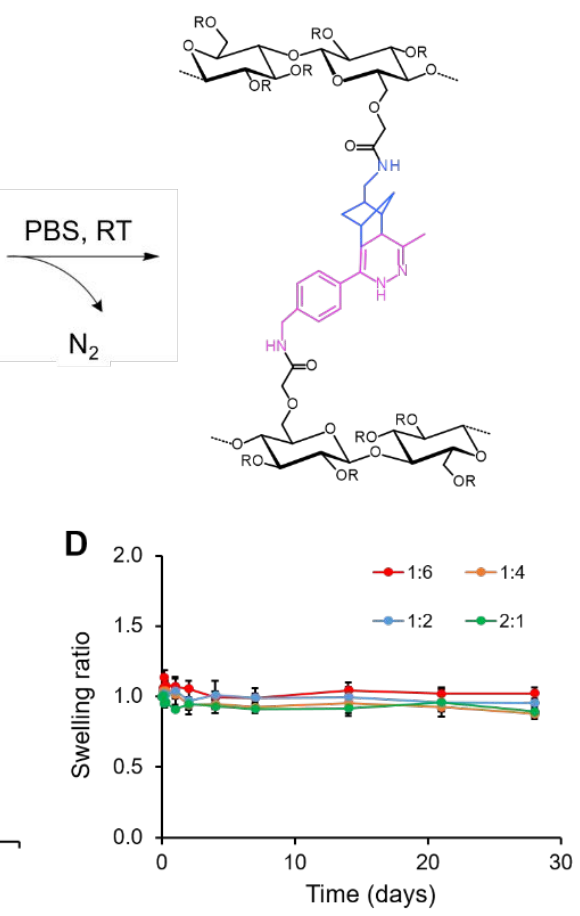

Figure S2. Inverse electron-demand Diels-Alder (IEDDA) MC hydrogels form under physiological $\mathrm{pH}$ and temperature, with tunable gelation time, stiffness matching that of brain tissue, and long-term stability. A) Schematic of IEDDA MC hydrogel synthesis, where norbornene-modified MC-norbornene reacts with MCtetrazine upon simple mixing, forming covalently crosslinked hydrogels under physiological conditions. B) Average gelation time of various IEDDA MC hydrogel formulations, at a fixed total $\mathrm{MC}$ concentration of $1 \%(\mathrm{w} / \mathrm{v})$, comparing different MC-Tz:MC-Norb ratios $(1: 6,1: 4,1: 2$ and 2:1) by rheometry $(\mathrm{n}=3$; mean $\pm \mathrm{SD})$. D) Evaluation of the Young's modulus of IEDDA MC hydrogels, at a fixed total MC concentration of $1 \%(w / v)$, comparing different MC-Tz:MC-Norb ratios (1:6, 1:4, 1:2 and 2:1) $(\mathrm{n}=3$; mean \pm SD). E) Swelling/stability study of $1 \%(\mathrm{w} / \mathrm{v}) \mathrm{MC}$ hydrogels at different MC-Tz:MC-Norb ratios (1:6, 1:4, 1:2 and 2:1). All of the formulations tested produced minimally-swelling and stable hydrogels, with $<5 \%$ 
variation in mass over $28 \mathrm{~d}(\mathrm{n}=3$; mean $\pm \mathrm{SD})$. Statistical significance was determined using one-way ANOVA with Tukey's post-hoc test: N.S. = not significant, ${ }^{*} \mathrm{p}<.05, * * \mathrm{p}<.01, * * * \mathrm{p}<.001$.

2:1 degradable MC gel

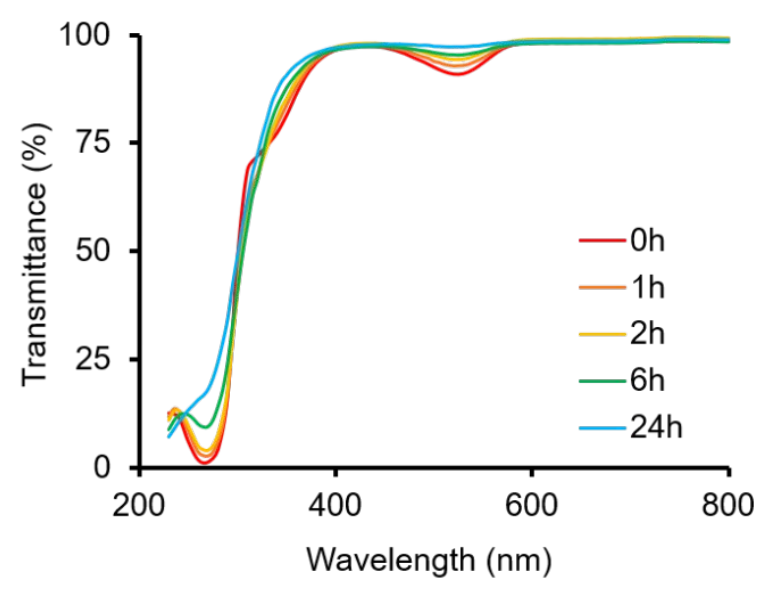

2:1 non-degradable MC gel

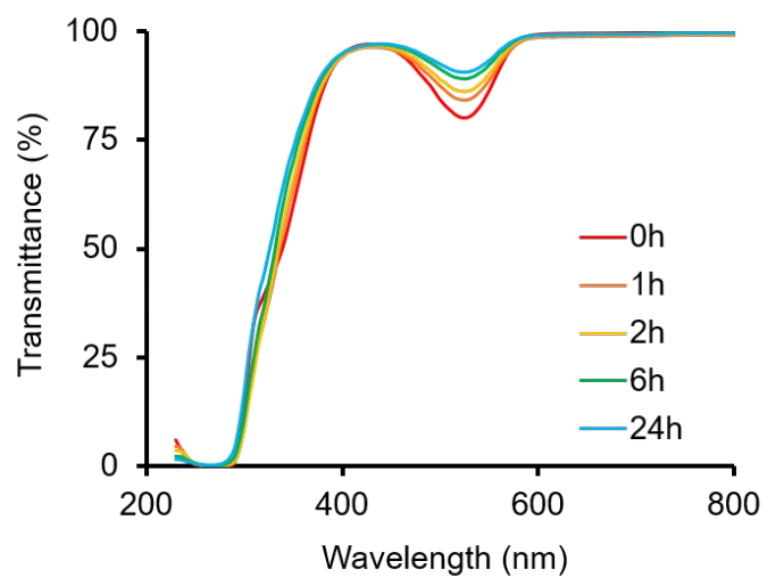

Figure S3. Transmittance over time of degradable and non-degradable IEDDA MC hydrogels during gelation, at a fixed concentration of $1 \%(\mathrm{w} / \mathrm{v}) \mathrm{MC}$ and a component ratio (MC-DTP-Tz:MC-Norb or MC-Tz:MC-Norb) of 2:1, under physiological $\mathrm{pH}$ and temperature. The increased transmittance at $525 \mathrm{~nm}$ with time confirms methylphenyltetrazine conversion upon crosslinking, which leads to materials that are highly transparent, and colorless (transmittance $>0.97$ ) to faintly pink (transmittance $>0.91$ ) depending on the degree of Tz substitution and the Tz:Norb ratio. 


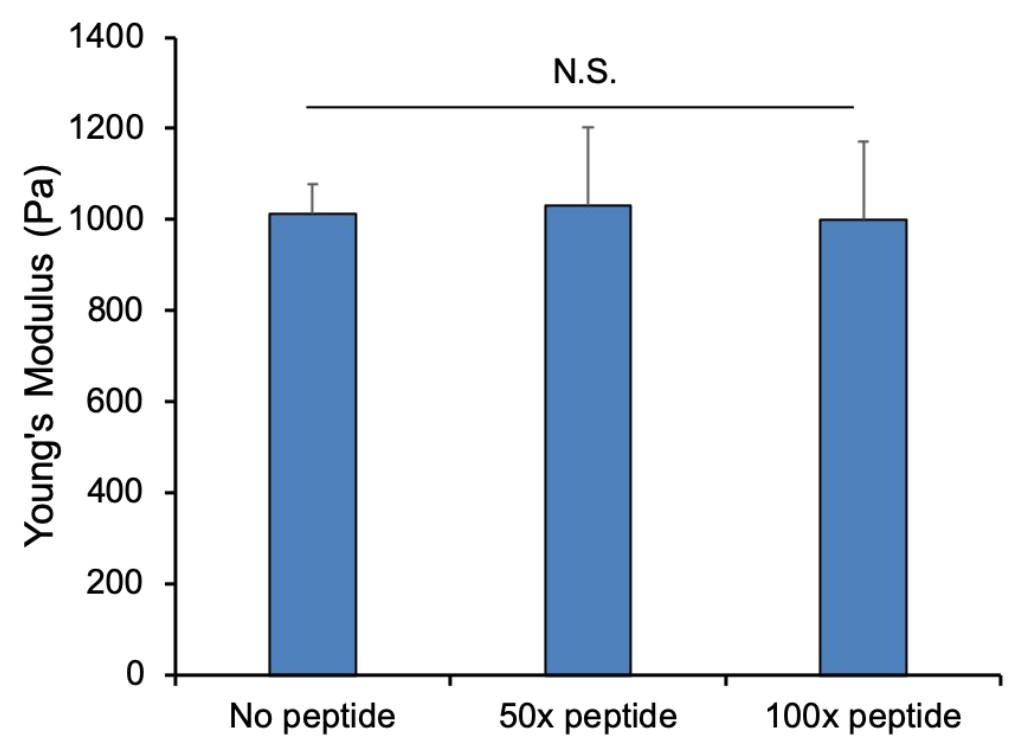

Figure S4. Evaluation of the Young's modulus of 1\% (w/v) IEDDA MC hydrogels (MC-Tz:MC-Norb ratio of 2:1), with norbornene-SH3 binding peptide concentrations corresponding to 0 (no peptide), 50 and 100 times molar excess. ( $n=3$, mean $\pm \mathrm{SD})$. 
A
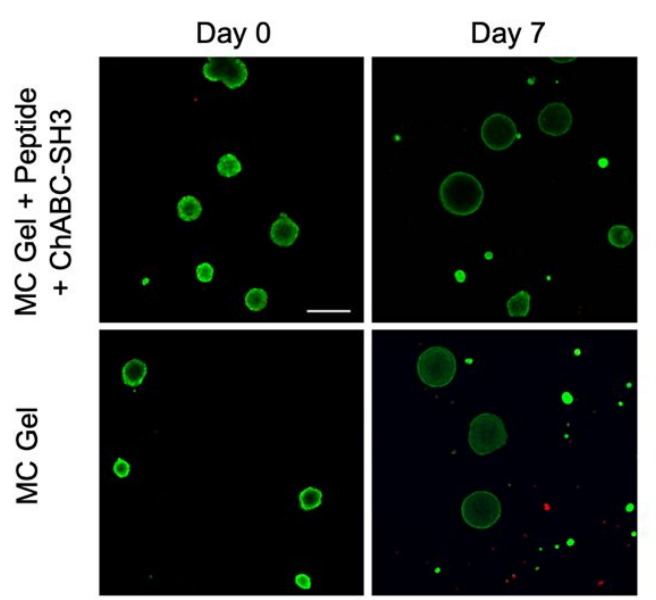

C

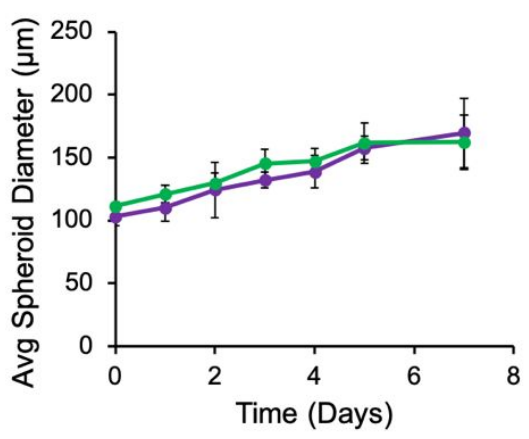

B

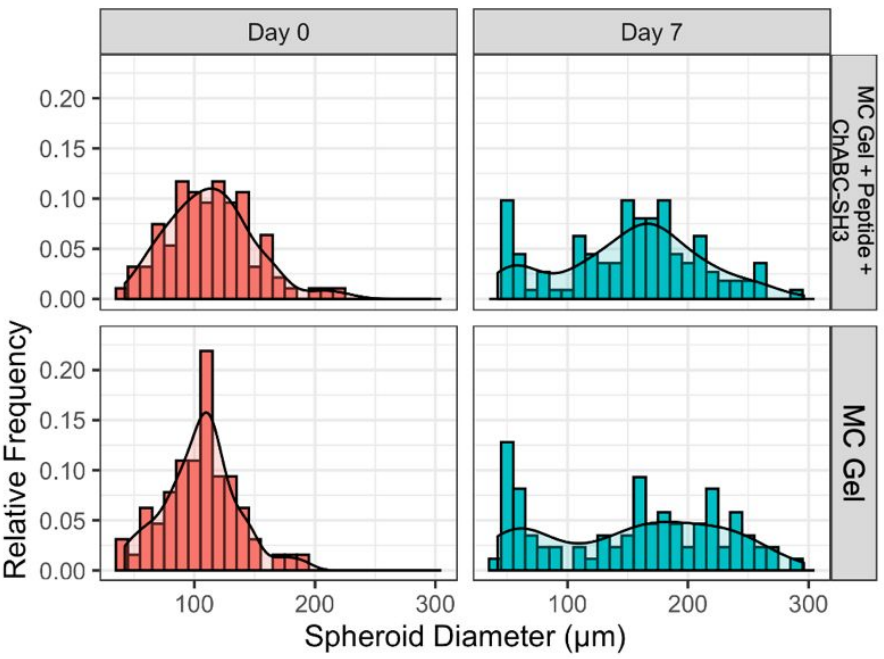

$\mathbf{E}$
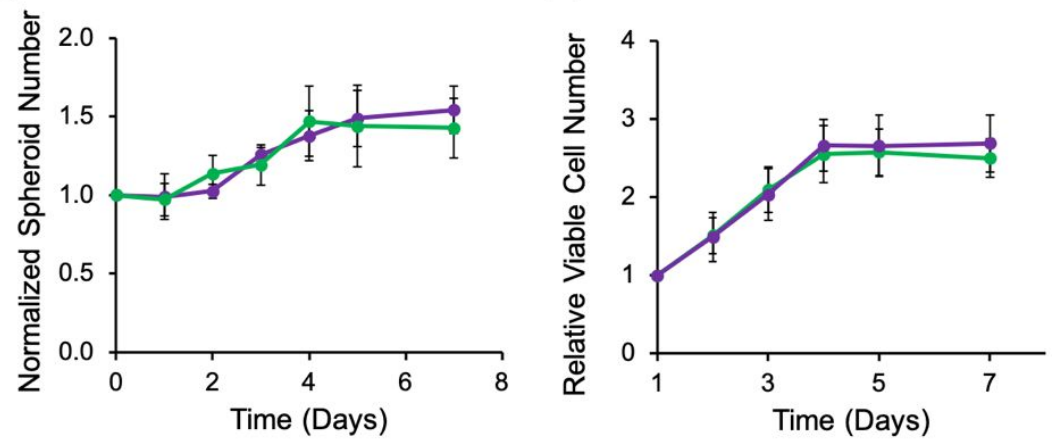

$\rightarrow-\mathrm{MC} \mathrm{Gel}+$ Peptide + ChABC-SH3 $\rightarrow-\mathrm{MC}$ Gel

Figure S5. Cytocompatibility of non-degradable IEDDA MC hydrogels with primary mouse progenitor cells. (A) Representative live/dead z-stack images of mNPC neurospheres encapsulated in non-degradable 1\% (w/v) IEDDA MC hydrogels (MC-Tz:MC-Norb ratio of 2:1) with and without SH3 binding peptides and ChABC-SH3 vs. those plated on tissue culture polystyrene (TCPS) (scale bar $=200 \mu \mathrm{M}) .(B)$ Neurosphere diameter distributions in IEDDA MC hydrogels vs. those on TCPS at days 0 and 7. ( $\mathrm{n}=3$, data pooled, bin size of $10 \mu \mathrm{m})$. (C) Average spheroid diameter, (D) Normalized spheroid number, and (E) Relative change in the number of viable cells in IEDDA MC hydrogels or on TCPS over $7 \mathrm{~d}$ in vitro $(\mathrm{n}=3)$. 


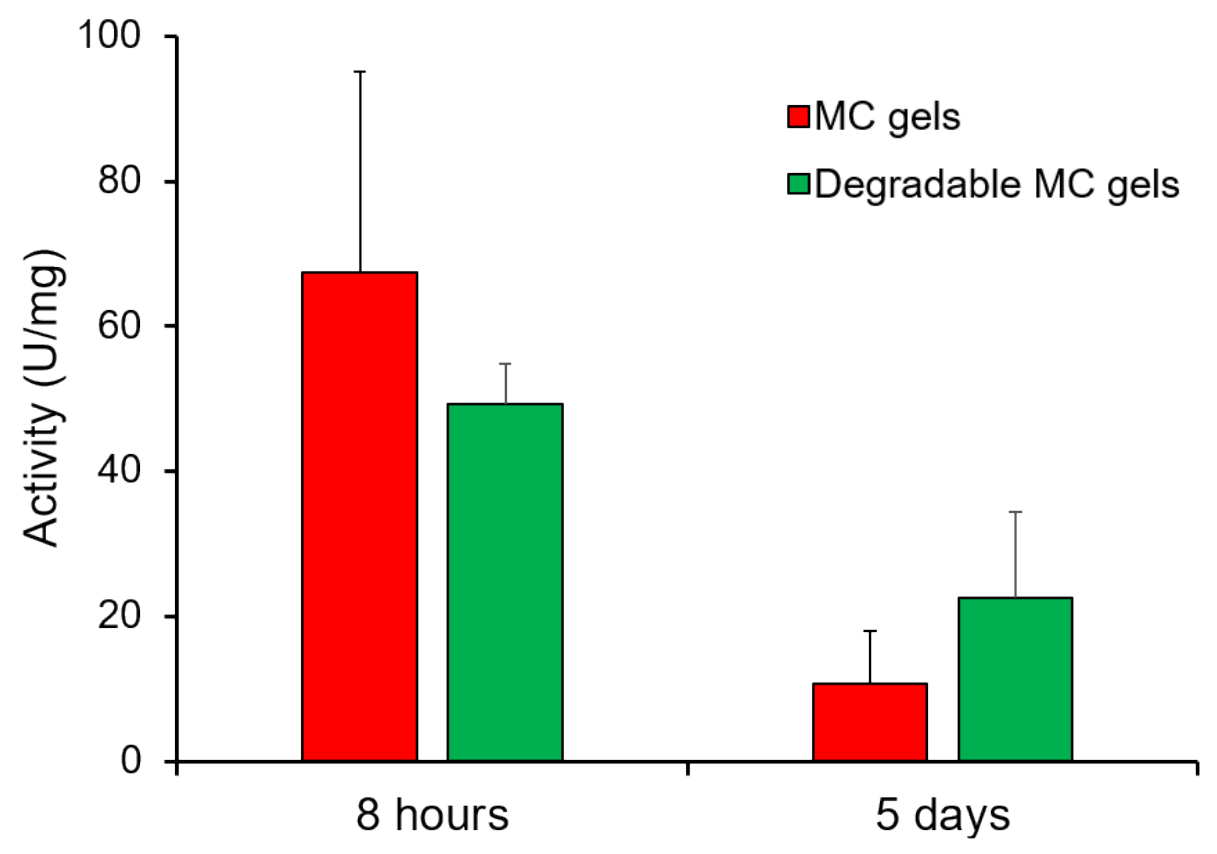

Figure S6. Specific activity of $\mathrm{ChABC-SH3}$ released from degradable and nondegradable 1\%(w/v) IEDDA MC hydrogels (MC-Tz:MC-Norb ratio of 2:1) containing mouse neural progenitor cell neurospheres. $(\mathrm{n}=3$, mean $\pm \mathrm{SD})$. 
Table S1: Summary of the compositions and physicochemical characteristics of the $1 \%(\mathrm{w} / \mathrm{v})$ degradable and non-degradable IEDDA MC hydrogels tested.

\begin{tabular}{|c|c|c|c|c|c|}
\hline & $\begin{array}{c}\text { Component } \\
\text { volume ratio } \\
\text { (Tz:Norb) }\end{array}$ & $\begin{array}{c}\text { Tz:Norb } \\
\text { molar ratio }\end{array}$ & $\begin{array}{c}\text { Theoretical } \\
\text { crosslink density } \\
\left(\mu \mathrm{mol} . \mathrm{mL}^{-1}\right)\end{array}$ & $\begin{array}{l}\text { gelation time } \\
\text { (min) }\end{array}$ & $\begin{array}{c}\text { Young's modulus } \\
\text { (Pa) }\end{array}$ \\
\hline \multirow[b]{2}{*}{ Non-degradable MC gels } & $1: 6$ & 0.39 & 0.27 & $10.6 \pm 1.7$ & $670 \pm 140$ \\
\hline & $1: 4$ & 0.58 & 0.38 & $5.5 \pm 0.9$ & $880 \pm 80$ \\
\hline MC-Norb & $1: 2$ & 1.16 & 0.55 & $3.2 \pm 1.1$ & $1430 \pm 190$ \\
\hline $\begin{array}{lc}(1.6 \% \\
\text { Norb sub. })\end{array}$ & $2: 1$ & 4.63 & 0.27 & $6.6 \pm 0.6$ & $1540 \pm 100$ \\
\hline \multirow{2}{*}{ Degradable } & $1: 6$ & 0.28 & 0.20 & $22.5 \pm 2.0$ & $510 \pm 110$ \\
\hline & $1: 4$ & 0.42 & 0.28 & $14.2 \pm 2.4$ & $550 \pm 100$ \\
\hline \multirow{2}{*}{$\begin{array}{cc}\text { MC-DTP-Tz } & \text { MC-Norb } \\
(1.6 \% \\
(2.8 \% \text { Tz sub. }) & \\
& \text { Norb sub. })\end{array}$} & $1: 2$ & 0.84 & 0.46 & $11.9 \pm 0.8$ & $1080 \pm 100$ \\
\hline & $2: 1$ & 3.36 & 0.27 & $12.8 \pm 1.9$ & $1270 \pm 80$ \\
\hline
\end{tabular}

Table S2: Parameters used for calculation of expected percent release ${ }^{1,2}$

\begin{tabular}{|c|c|}
\hline Parameter & Value \\
\hline$L$ & $4 * 10^{-3} \mathrm{~m}$ \\
\hline$D$ & $6.8 * 10^{-11} \mathrm{~m}^{2} \mathrm{~s}^{-1}$ \\
\hline$K_{D}$ & $2.7 * 10^{-5} \mathrm{~mol} * \mathrm{~L}^{-1}$ \\
\hline$k_{\text {off }}$ & $10^{4} \mathrm{~s}^{-1}$ \\
\hline$C_{\text {protein }, 0}$ & $1.52 * 10^{-6} \mathrm{~mol} * \mathrm{~L}^{-1}$ \\
\hline$C_{\text {peptide }, 0}$ & $7.6 * 10^{-5} \mathrm{~mol} * \mathrm{~L}^{-1}(50 x)$ or $1.52 *$ \\
& $10^{-4} \mathrm{~mol} * L^{-1}(100 x)$ \\
\hline$t$ & $604800 \mathrm{~s}$ \\
\hline$T$ & $298 \mathrm{~K}$ \\
\hline$\mu$ & $8.9 * 10^{-4} \mathrm{pa} * \mathrm{~s}$ \\
\hline$M W_{\text {pro }}$ & $131530 \mathrm{Da}$ \\
\hline
\end{tabular}


The controlled release regime is characterized by the dimensionless quantities

$\beta$ and $\gamma$ :

$$
\begin{aligned}
& \beta=\frac{L^{2} * k_{\text {off }}}{D} \gg 1 \\
& \gamma=\frac{C_{\text {free protein }, 0}}{K_{D}} \ll 1
\end{aligned}
$$

Where $k_{\text {off }}$ is the rate of ChABC-SH3 peptide dissociation, and $C_{\text {free protein }, 0}$ is the amount of unbound protein initially. The diffusivity $D$ of the protein through the hydrogel was assumed to be the same as the diffusivity of the protein through water due to the high water content of the hydrogel ( $99 \mathrm{wt} \%$ ), and can be estimated using the Stokes-Einstein-Sutherland equation: ${ }^{39}$

$$
D=\frac{9.940 * 10^{-15} * T}{\mu * \sqrt[3]{M W_{\text {pro }}}}
$$

$C_{\text {free protein }, 0}$ is the concentration of unbound $\mathrm{ChABC-SH} 3$ in an equilibrated gel at $t=0$ and can be calculated using the equation for $K_{D}$ :

$$
K_{D}=\frac{\left(C_{\text {total protein }, 0}-C_{\text {complex }}\right) *\left(C_{\text {free peptide }, 0}-C_{\text {complex }}\right)}{C_{\text {complex }, 0}}
$$

Solving for $C_{\text {complex }, 0}$ enables calculation of $C_{\text {free protein }, 0}$ through the equation

$$
C_{\text {free protein }, 0}=\left(C_{\text {total protein }, 0}-C_{\text {complex }}\right)
$$

The values of the dimensionless quantities for 50x peptide molar excess are:

$$
\beta=\frac{L^{2} * k_{o f f}}{D}=2.4 * 10^{9} \gg 1
$$




$$
\gamma=\frac{C_{\text {free protein }, 0}}{K_{D}}=4.03 * 10^{-7} \ll 1
$$

Thus satisfying the conditions for the controlled release regime.

Table S3: Summary of results of cumulative release estimation for different peptide concentrations

\begin{tabular}{|c|c|c|}
\hline Peptide concentration & $\boldsymbol{t}^{*}$ & Cumulative Release (\%) \\
\hline $76 \mu M(50 \mathrm{x}$ excess $)$ & 0.68 & $71 \%$ \\
\hline $152 \mu M(100 \mathrm{x}$ excess $)$ & 0.38 & $55 \%$ \\
\hline
\end{tabular}

\section{References}

(1) Vulic, K.; Pakulska, M. M.; Sonthalia, R.; Ramachandran, A.; Shoichet, M. S. Mathematical Model Accurately Predicts Protein Release from an AffinityBased Delivery System. J. Control. Release 2015, 197, 69-77. https://doi.org/10.1016/j.jconrel.2014.10.032.

(2) Vulic, K.; Shoichet, M. S. Tunable Growth Factor Delivery from Injectable Hydrogels for Tissue Engineering. J. Am. Chem. Soc. 2012, 134 (2), 882-885. https://doi.org/10.1021/ja210638x. 